\title{
Synthesis of copper nanoparticles for use in an optical initiation system
}

\author{
V. M. Pugachev ${ }^{1}$, K. A. Datiy ${ }^{2}$, A. S. Valnyukova ${ }^{1}$, M. V. Ananyeva ${ }^{1}$, A. V. Kalenskii ${ }^{1}$ \\ ${ }^{1}$ Kemerovo state University, Kemerovo, 650043, Russia \\ ${ }^{2}$ Institute of Coal Chemistry and Material Science SB RAS, Kemerovo, 650000, Russia \\ kriger@kemsu.ru
}

PACS 61.46. $+\mathrm{w}, 82.33 . \mathrm{Vx}$

DOI 10.17586/2220-8054-2015-6-3-361-365

In this work, the modes of synthesizing copper nanoparticles for use in an optical initiation system were proposed. The optimal sizes of the copper particles in the pentaerythritol tetranitrate were estimated, for use as a cup of the optical detonator on the first and the second harmonics of the Nd:Yag laser. For the first harmonic of the Nd:Yag, laser the absorptivity maximum was 0.097 and the particle's radius was $98 \mathrm{~nm}$, for the second harmonic, the absorptivity maximum rose more than in 34 times, and it was equal to 3.29 and the copper particle's radius was $30 \mathrm{~nm}$. Comparison of the calculated critical energy densities shows that pentaerythritol tetranitrate, which contains the copper nanoparticles, must be significantly more sensitive ( $\sim 29$ times $)$ to the second harmonic than to the first. The modes of synthesis for copper nanoparticles of the required size were determined and tested.

Keywords: Hot spot model, laser initiation, metal nanoparticles absorption, copper nanoparticles, synthesis of nanoparticles.

Received: 19 January 2015

\section{Introduction}

Metal nanoparticles with the definite sizes and shapes are currently found in wide use in optical and electronic equipment [1], chemical, biochemical sensors and catalysts [2-4]. In works [5-6] the potential for using gold and silver nanoparticles as a part of the composites with a transparent medium for an optical detonator's cup was shown. In contrast to the iron-group [7-8] and aluminium-group elements, for which the maximal absorptivities $\left(Q_{a b s}\right)$ do not exceed 2.5, silver and gold nanoparticles $Q_{a b s}$ have values more than 6 [6]. One way to enhance the safety of using energetic materials-based equipment based is to develop optical initiation systems. Explosives in these systems must have selective sensitivity to irradiation and at the same time have low sensitivity to sound waves and impact [10]. In work [11], the initiation threshold values were determined for the pentaerythritol tetranitrate, containing aluminium nanoparticles. The composites were shown to have laser sensitivity about $1 \mathrm{~J} / \mathrm{cm}^{2}$, this value is in 100 times smaller than that of pure pentaerythritol tetranitrate pressed pellet. That is why the main direction of optical detonators development is the doping of the existing explosives with the light sensitive impurities [5]. At the same time, one of the most important questions is the synthesis of the stable nanoparticles of the required size. The aim of this work is to define the optimal nanoparticle size for use in the cup of an optical detonator, and to determine the synthetic method for those nanoparticles. To achieve the object it is necessary:

1) to calculate the optical properties of the copper nanoparticles in the pentaerythritol tetranitrate pressed matrix for the first and the second harmonics of the Nd:Yag laser; 
2) to calculate the minimal initiation energy density of explosive decomposition of the pentaerythritol tetranitrate containing copper nanoparticles taking into account the absorptivities obtained in step 1 ;

3) to determine and test methods for the synthesis of properly-sized copper nanoparticles.

\section{Hot spot model}

Experimental solution of the first and second point is a very laborious task, even for one wavelength [12-13]. That is why the absorptivities $\left(Q_{a b s}\right)$ of the spherical nanoparticles with radii $\mathrm{R}$ were calculated in terms of Mie theory using the method described in [14].

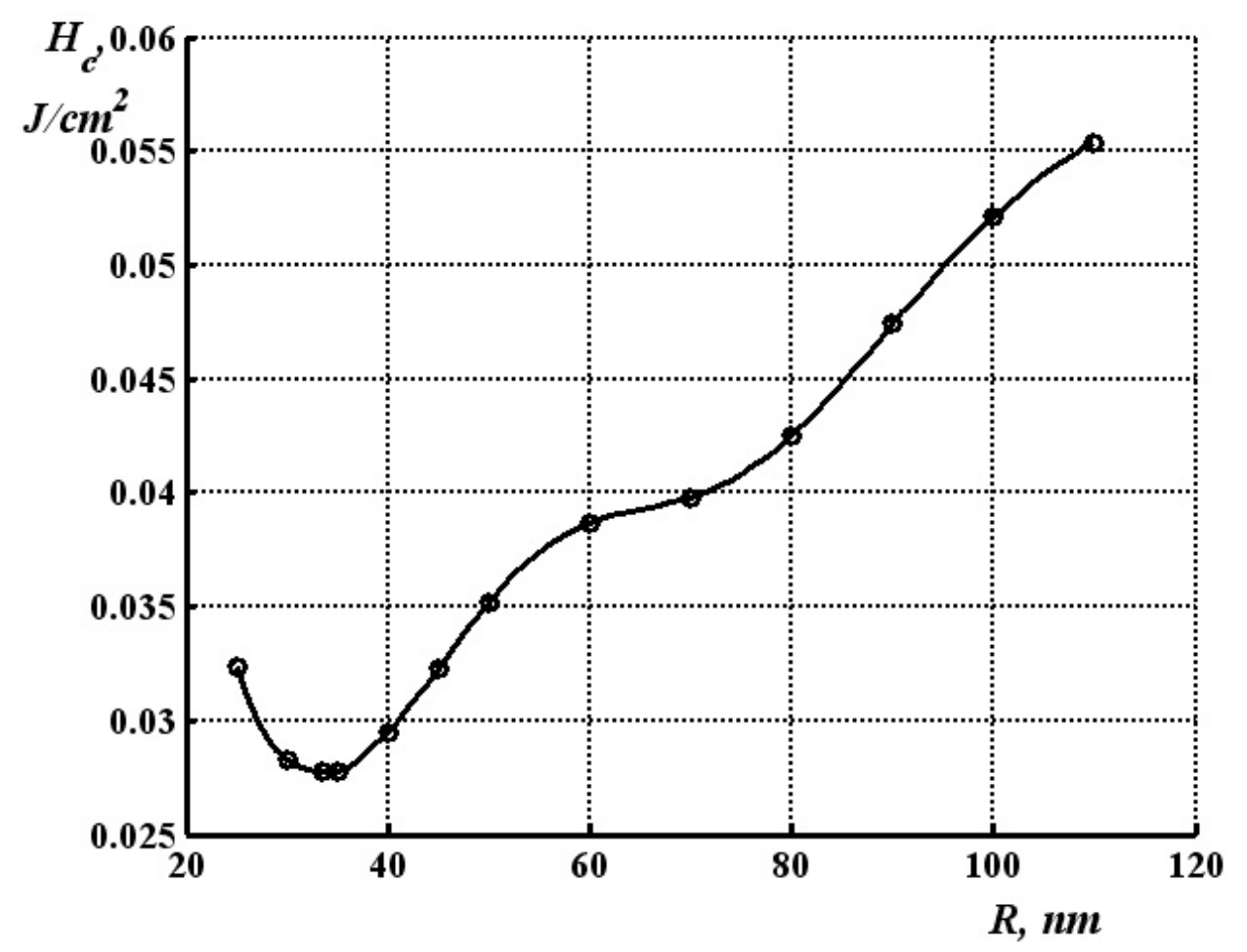

FIG. 1. Dependence of the critical initiation energy of the pentaerythritol tetranitrate on the copper nanoparticles' radii for the $532 \mathrm{~nm}$ wavelength

To calculate the absorptivity, it is necessary to use the complex refractive index $\left(\mathrm{m}_{i}\right)$, which also depends on the wavelength of the incident irradiation [11]. In work [15], the $\mathrm{m}_{i}$ for copper was estimated to be $0.85-2.39 \mathrm{i}$ for the first harmonic $(1064 \mathrm{~nm})$ of the Nd:Yag laser and 0.21-7.0 i for the second harmonic $(532 \mathrm{~nm})$. For each wavelength, the dependences $Q_{a b s}(R)$ were calculated. These dependences have maxima $\left(Q_{a b s \text { max }}\right)$ whose positions $\left(R_{a b s \max }\right)$ depend on the wavelength. For the first harmonic of the Nd:Yag laser, $Q_{a b s \max }=0.097$ and $R_{a b s \max }=98 \mathrm{~nm}$, for the second harmonic, $Q_{a b s \text { max }}$ increases to 3.29 and $R_{a b s \text { max }}$ decreases to $30 \mathrm{~nm}$.

The considerable (more than in 34-fold) increase of $Q_{a b s}$ max comparing two harmonics must give the corresponding decrease of the energy density $\left(H_{c}\right)$, required to initiate the explosive decomposition of the pentaerythritol tetranitrate - copper system. Model of initiation of the explosive decomposition in the vicinity of the absorbing particle and the method 
of the calculation was presented in previous works [16-17]. The minimal value of the critical energy density $\left(H_{c}\right.$ min $)$ for the pentaerythritol tetranitrate - copper system, calculated in terms of the model for the first harmonic, was $0.82 \mathrm{~J} / \mathrm{cm}^{2}$ while $R_{\min }=96 \mathrm{~nm}$. Figure 1 shows the dependence $H_{c}(R)$ calculated for copper nanoparticles at a wavelength of $532 \mathrm{~nm}$. The dependence has a strongly marked minimum, which corresponds to the minimal energy density necessary to transition the reaction into a self-accelerated mode. The coordinates for the minimum are $H_{c m i n}=0.0278 \mathrm{~J} / \mathrm{cm}^{2}$ and $R_{\text {min }}=33.5 \mathrm{~nm}$.

Comparing the calculated critical energy densities shows that pentaerythritol tetranitrate, containing copper nanoparticles, acted upon by the second harmonic of Nd:Yag laser has a considerably smaller critical energy density (by 29 times) than that of the first harmonic. For the optical detonator cups using the first harmonic, the optimal size of copper particles is about $200 \mathrm{~nm}$, for the second harmonic, the ideal size is $60-70 \mathrm{~nm}$. The following stage of research is to work out the methods of synthesis of the copper with required sizes.

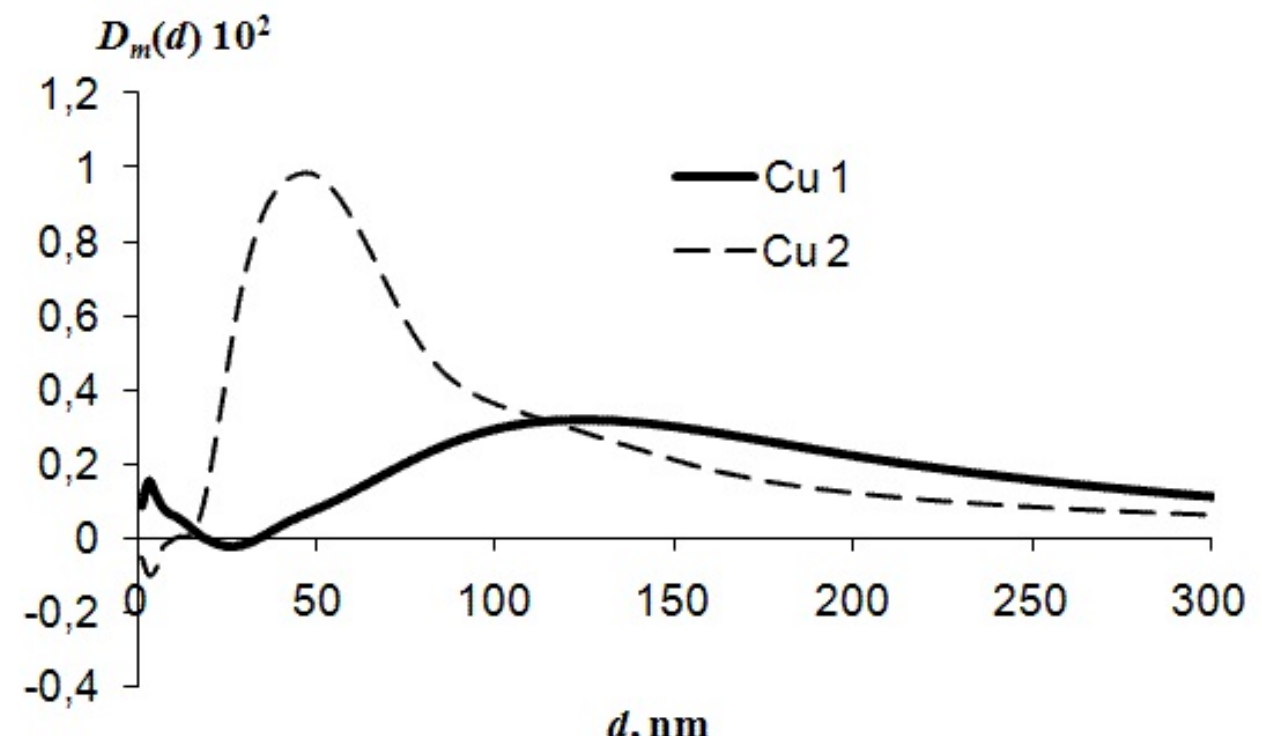

Fig. 2. Typical mass contribution function of the heterogeneity on size. The samples were got using regimes "A" (1) and "B" (2)

\section{Synthesis of copper nanoparticles}

Different methods of synthesizing the copper particles are known. In work [18] copper nanoparticles of different diameters (from 3 till $22 \mathrm{~nm}$ ) were obtained by the reduction of copper sulfate and ascorbic acid in an aqueous solution of ethylene glycol (sodium borohydride was used as a reducing agent), this caused the existence the copper(I) oxide impurity in the copper nanoparticles. The abundance of the copper(I) oxide varied from $11.5 \%$ to $44.1 \%$ depending on the conditions of the reaction. For optical detonators, it is necessary to use nanoparticles with considerably larger diameters which have oxidation-free surfaces.

In this work, the synthesis of $\mathrm{Cu}$ nanoparticles was performed in an "Anton Paar" reactor. The copper hydroxide, deposited by alkali (NaOH, 99 wt.\%) in an aqueous solution of the copper chloride (analytical grade), and then, the in situ-formed hydroxide was reduced by hydrazine hydrate. Conditions were optimized taking into account the methods for obtaining two-component powders $\mathrm{Fe}-\mathrm{Co}, \mathrm{Fe}-\mathrm{Ni}$ and $\mathrm{Cu}-\mathrm{Ni}$ [19-23]. We have also determined the optimal conditions for obtaining copper of one phase, which was proved by the results of 
the radiographic analysis. Akali $2-3 \mathrm{~g}(\sim 0.3 \mathrm{~mol} / \mathrm{l})$ and reducing agent $15-20 \mathrm{ml}(\sim 3 \mathrm{~mol} / \mathrm{l})$ are added to $100 \mathrm{ml}$ (assuming 1 gram of metal) of the reaction mixture, which temperature was $80-85^{\circ}$. Then, in mode $\mathrm{A}$ the mixture of alkali salt and hydrazine are added simultaneously, in mode B the alkali salt is added prior to the hydrazine. A compulsory condition for synthesis is intense agitation (mechanical stirrer of "squirrel cage" type). All steps of the process were performed using equipment that permitted the use of an inert atmosphere and excluded all contact of the reactants with air.

Immediately after synthesis and washing, the powder was placed in a weighing bottle and stored under glycerin. The main purpose of the synthesis under a nitrogen atmosphere is to obtain metal nanoparticles having a minimal percentage of the oxidized impurity phase.

Determination of the phase composition and structural parameters was performed using X-ray diffractometer Difreii-401 (Russia) and DRON-3. The average particle size was determined by the method of small-angle X-ray scattering in copper irradiation using PFC-1 apparatus. Copper nanoparticles, synthesized in mode A, had diameters $(d)$ from 100 to $300 \mathrm{~nm}$ (fig. 2 (1)); while mode B gave particles with diameters of about $60 \mathrm{~nm}$ (fig. 2 (2)). Data from the small-angle X-ray scattering agreed with the results of the diffraction peak broadening calculation, which gave the particles' sizes of about $50 \mathrm{~nm}$. Thus, the analyzed powders might be considered nanopatterned.

The mass size contribution function has areas with the minima below zero (area of sizes up to $5 \mathrm{~nm}$ ), this is because of a thin film of oxide on the particles' surfaces. The average thickness of the layer is $2.5 \mathrm{~nm}$. When comparing the experimental data, one readily sees that when changing the synthetic method, the copper nanoparticles' average sizes decrease from 100-200 nm (mode A) to $60 \mathrm{~nm}$ (mode B).

\section{Conclusion}

In this presented work, synthetic methods for copper nanoparticles for use in optical initiation system were proposed. Optimal sizes were estimated for copper particles in pentaerythritol tetranitrate, used as the cup of an optical detonator, for the first and the second harmonics of the Nd:Yag laser. For the first harmonic, $Q_{a b s} \max =0.097$ and $R_{a b s \max }$ $=98 \mathrm{~nm}$, for the second harmonic $Q_{a b s} \max$ rises to 3.29 and $R_{a b s} \max$ decreases to $30 \mathrm{~nm}$. Calculated for the first harmonic, $H_{c m i n}$ of the pentaerythritol tetranitrate - copper system is $0.82 \mathrm{~J} / \mathrm{cm}^{2}$ and the particle's radius $R_{\min }=96 \mathrm{~nm}$. It was shown that pentaerythritol tetranitrate, containing the copper nanoparticles, must be significantly more sensitive ( $\sim 29$ times) to the second harmonic of the Nd:Yag laser than to the first. Methods for the synthesis of properly-sized copper nanoparticles were worked out and tested. The next step for the optimization of the optical detonator cup is to experimentally determine the critical initiation energy density for pentaerythritol tetranitrate, containing the copper nanoparticles of different diameters, for the first and the second harmonics of the Nd:Yag laser. This work was supported by Ministry of Education and Science of the Russian Federation (governmental project No. 2014/64) and Russian Foundation for Basic Research for the financial support (grant 14-03-31648).

\section{References}

[1] Yang G., Zhang Z., et al. Synthesis and characterization of highly stable dispersions of copper nanoparticles by a novel one-pot method. Materials Research Bulletin, 2013, 48, P. 1716.

[2] Patolsky F., Zheng G., et al. Nanowire-based biosensors. Analytical Chemistry, 2006, 78(13), P. 42604269. 
[3] Wang J. Carbon-nanotube based electrochemical biosensors: A review. Electroanalysis, 2005, 17, P. 714.

[4] Paxton W. F., Sen A., Mallouk T. E. Motility of catalytic nanoparticles through self-generated forces. Chemistry - A European Journal, 2005, 11, P. 6462-6470.

[5] Ananyeva M.V., Zvekov A.A., et al. Promising compounds for the cap of optical detonator. Perspektivnye materialy, 2014, 7, P. 5-12.

[6] Lukatova S.G. Calculation of the PETN-gold composites' absorptivity for the second harmonic of the ND:YAG laser. Mezhdunarodnoe nauchnoe izdanie Sovremennye fundamental'nye $i$ prikladnye issledovanija, 2014, 1(12), P. 95-98.

[7] Ananyeva M.V., Kalenskii A.V., et al. Kinetic regularities of explosive decomposition of PETN contaning aluminium, cobalt and nickel nanoparticles. Bulletin of Kemerovo state university, 2014, 1-1(57), P. 194-200.

[8] Kalenskii A.V., Ananyeva M.V., et al. Spectrum dependence of the critical energy density of composites based on pentaerythritol tetranitrate with nikel nanoparticles. Fundamental'nye problemy sovremennogo materialovedenia, 2014, 11(3), P. 340-345.

[9] Kalenskii A.V., Zvekov A.A., et al. Influence of the laser irradiation wavelength on the energetic materials' initiation critical energy. Fizika goreniya i vzryva, 2014, 50(3), P. 98-104.

[10] Kalenskii A.V., Kriger V.G., et al. The Microcenter Heat Explosion Model Modernization. Izvestia Vuzov Fizika, 2012, 55(11-3), P. 62-66.

[11] Aduev B.P., Nurmukhametov D.R., et al. Vzryvchatoye razlozheniye TENa s nanodobavkami alyuminiya pri vozdeystvii impulsnogo lazernogo izlucheniya razlichnoy dliny volny. Khimicheskaya fizika, 2013, 32(8), P. 39-42.

[12] Aduev B.P., Nurmukhametov D.R., et al. Integrating Sphere study of the optical properties of aluminum nanoparticles in tetranitropentaerytrite. Zhurnal Tekhnicheskoi Fiziki, 2014, 84(9), P. 126-131.

[13] Zvekov A.A., Ananyeva M.V., et al. Regularities of light diffusion in the compo site material pentaerythritol tetranitrate - nickel. Nanosystems: physics, chemistry, mathematics., 2014, 5(5), P. 685-691.

[14] Kriger V.G., Kalenskii A.V., et al. Vliyaniye effektivnosti pogloshcheniya lazernogo izlucheniya na temperaturu razogreva vklyucheniya v prozrachnykh sredakh. Fizika goreniya $i$ vzryva, 2012, 48(6), P. 54-58.

[15] Gazenaur N.V., Zykov I.Yu., et al. The wavelength dependence of copper absorption. Aspirant, 2014, 5, P. 94-98.

[16] Aduev B.P., Ananyeva M.V., et al. Miro-hotspot model for the laser initiation of explosive decomposition of energetic materials with melting taken into account. Fizika goreniya $i$ vzryva, 2014, 50(6), P. 92-99.

[17] Kriger V.G., Kalenskii A.V., et al. Protsessy teploperenosa pri lazernom razogreve vklyucheny v inertnoy matritse. Teplofizika i aeromekhanika, 2013, 20(3), P. 375-382.

[18] Avchinnikova E.A., Vorob'eva S.A. Sintez i svoistva nanochastits medi, stabilizirovannykh polietilenglikolem. Vestnik BGU, 2013, 2(3), P. 12-16.

[19] Zaharov Yu.A., Pugachev V.M., et al. Nanosize powders of transition metals binary systems. J. Phys.: Conf. Ser., 2012, 345(1), P. 12024.

[20] Pugachev V.M., Datiy K.A., et al. Study of products of nanoscale systems Fe-Co-Ni synthesis. Bulletin of Kemerovo state university, 2013, 55(3), P. 77-80.

[21] Zaharov Yu.A., Pugachev V.M., et al. Chemical synthesis, structure and magnetic properties of nanocrystalline Fe-Co alloys. Materials Letters, 2012, 74, P. 173-175.

[22] Pugachev V.M., Dodonov V.G., et al. Fazovyi sostav i nekotorye svoistva nanorazmernykh poroshkov Ni-Co i Ni-Cu. Persptktivnye materialy, 2011, 11, P. 156-163.

[23] Datiy K.A., Zakharov Yu.A., Khitsova L.M. Termostimyliryemye protsessy na poverkhnosti nanostryktyrirovannykh poroshkov Fe-Co-Ni. Bulletin of Kemerovo state university, 2014, 3-3(59), P. 184-188. 